\title{
The difficult diagnosis of pulmonary vascular disease in heart failure
}

\author{
Robert Naeije ${ }^{1}$ and Anna Ryan Hemnes ${ }^{2}$ \\ Affiliations: ${ }^{1}$ University of Brussels, Brussels, Belgium. ${ }^{2}$ Vanderbilt University, Nashville, TN, USA. \\ Correspondence: Robert Naeije, Dept of Cardiology, Erasme Campus CP 604, 808 Lennik Road, B-1070 \\ Brussels, Belgium. E-mail: rnaeijedulb.ac.be
}

0 @ERSpublications

A step forward in the diagnosis of pulmonary vascular disease in patients with left heart failure http://ow.ly/kR47300mzcf

In this issue of the European Respiratory Journal (ERJ), GERGES et al. [1] propose an interesting refinement of the diagnosis of pulmonary vascular disease in patients with left heart failure. The problem is of importance. Left heart disease with increased pulmonary venous pressure, abbreviated as LHD in recent reviews and guidelines, is by far the most common cause of pulmonary hypertension (PH) [2-4]. Furthermore, up to $80 \%$ of patients with heart failure with preserved or reduced ejection fraction and/or mitral or aortic valve diseases are exposed to the eventual development of $\mathrm{PH}$ with associated worsened symptomology and decreased survival [2-4].

Accordingly, the diagnosis of PH-LHD was a focus of attention at the World PH Symposium held in Nice in 2013. Experts agreed on the following updated invasive haemodynamic criteria of PH-LHD: a mean pulmonary artery pressure (PAP) $\geqslant 25 \mathrm{mmHg}$ and a pulmonary artery wedge pressure (PAWP) $>15 \mathrm{mmHg}$ to define post-capillary $\mathrm{PH}$, with a gradient between diastolic PAP and PAWP, or diastolic pressure gradient $(\mathrm{DPG}) \geqslant 7 \mathrm{mmHg}$ and/or a pulmonary vascular resistance $(\mathrm{PVR})>3$ Wood units (WU) to identify a pre-capillary component added to the passive upstream transmission of PAWP. New acronyms were introduced: Ipc-PH for isolated post-capillary PH with normal or minimally increased DPG and PVR, and Cpc-PH for combined pre- and post-capillary PH with definitely increased DPG and/or PVR [2-4].

GERGES et al. [1] implemented these criteria in an in-depth analysis of a database of 1506 patients diagnosed with PH-LHD. Their analysis convincingly shows that the combination of a DPG $\geqslant 7 \mathrm{mmHg}$ and (instead of and/or) a PVR $>3 \mathrm{WU}$ provides a greater specificity for the Cpc-PH phenotype. Tightened criteria decreased the prevalence of pulmonary vascular disease in LHD by $42 \%$ in their patient population. This difference is not trivial. GERGES and co-workers $[5,6]$ had previously shown that Cpc- $\mathrm{PH}$ as a complication of heart failure with or without preserved ejection fraction, or increased risk of pulmonary vascular disease in these patients is associated with more severe $\mathrm{PH}$, worse functional class, more commonly altered right ventricular function and decreased survival, when compared with Ipc- $\mathrm{PH}$.

The debate about the best combination of measurements to predict morphological changes in the pulmonary circulation is not new. When Cournand et al. [7] reported in 1945 the first cardiac catheterisation of a patient, who happened to suffer from severe $\mathrm{PH}$ on mitral stenosis, the histopathology of this form of PH-LHD had already been extensively described [8]. Obviously, increased PAP was to be accounted for by remodelling and obstruction of pulmonary resistive vessels. However, progress of cardiac surgery to correct for increased pulmonary venous pressure (mitral stenosis) or high pulmonary flow (left-to-right cardiac shunts) as causes of severe PH soon requested more detailed haemodynamic criteria of severity and reversibility of increased PAP. It was indeed realised that patients with severe PH were a major operative risk and post-operative persistent increase in PAP could preclude any benefit from the procedure anyway.

Received: April 202016 | Accepted after revision: April 252016

Conflict of interest: None declared.

Copyright OERS 2016 
In 1958, WOOD [9] reasoned on the PVR equation re-written as mean PAP=PVR $\times$ cardiac output $+\mathrm{PAWP}$, to identify "passive" (thus reversible) versus "out of proportion" or "reactive" (thus potentially irreversible) increases in PAP. He defined PH by a mean PAP far above the upper limit of normal, which he had established at $20 \mathrm{mmHg}$ from right heart catheterisations in 60 healthy volunteers recruited in the Brompton hospital. He further thought that irreversible $\mathrm{PH}$ would correspond to an out of proportion upstream transmission of PAWP and/or to $>1-2 \mathrm{mmHg}$ increase in mean PAP per litre of cardiac output increased during exercise. Patients with thus determined "out of proportion" PH underwent extensive vasodilator testing to establish the lowest possible PVR as an indication of irreversible structural changes in the pulmonary circulation. The same reasoning has been extended to patients referred for cardiac transplantation, although often with only the numerator of the PVR equation, or transpulmonary pressure gradient (TPG), as it was found out that consideration of cardiac output did not much add to the prediction of outcome in these patients $[10,11]$.

The cut-off values of the TPG applied for the diagnosis of pre-capillary PH-LHD have evolved over time, from $10 \mathrm{mmHg}$ in the 1950s-1970s [9, 12], to $12 \mathrm{mmHg}[2-4]$ and, most recently, to 14 or $15 \mathrm{mmHg}[11$, 13]. It was indeed realised that patients with $\mathrm{PH}$ and a TPG $>12 \mathrm{mmHg}$ could nevertheless present with a return of PAP to normal along with a normalised PAWP by interventions such as high-dose diuretics combined with inotropes or, more radically, cardiac transplantation [14]. This turned the attention to the DPG, which was actually proposed in the 1970s to diagnose pulmonary vascular complications of acute respiratory failure and shock [15]. HARVEY et al. [16] had shown in the late 1960s and early 1970s that the DPG was less sensitive than the TPG to decreased pulmonary vascular compliance, which necessarily accompanies any increase in PAWP, and insensitive to flow, which is essentially systolic. Harvey's modelling was recently actualised with theoretical demonstration that an increase in PAWP to $15 \mathrm{mmHg}$ may or may not be accompanied by an increase in the TPG above $12 \mathrm{mmHg}$ depending on residual resistive vessel distensibility, but that a TPG $>12 \mathrm{mmHg}$ would inevitably occur with an increased PAWP above $20 \mathrm{mmHg}$, while the DPG would either remain constant or even decrease with increasing levels of PAWP [14].

Why then combine the DPG with PVR? The DPG is normally small, and thus exposed to relatively large errors on the measurement. Suppose the precision of it is $\pm 5 \mathrm{mmHg}$, which is far better than in most catheterisation laboratories' daily life [17], and the "true" DPG is equal to zero, which is reasonable in healthy subjects with a high-normal PAWP [14]. The measured DPG will then be negative in half of the cases. Conversely, a high-normal DPG would be measured at $>7 \mathrm{mmHg}$ in a significant proportion of cases as well. Combining the DPG with the TPG, as was implemented in a previous study by GERGES et al. [5], or rather with PVR as now recommended [1], is essential to limit single number-derived false positives or negatives.

The (re)introduction of the DPG for the differential diagnosis of PH-LHD has stirred some controversy about its relevance to prognostication. TAMPAKAKIs et al. [18] reported that poor outcome in PH-LHD was related to a low rather than to a high DPG. However, very low DPG may occur in case of rapid rise in PAWP and slower rise in diastolic PAP and mean PAP related to preserved resistive vessel distensibility in acute or subacute heart failure, in itself of poor prognosis. This may explain why the prediction of outcome on the basis of a DPG is actually biphasic [19]. Conversely, the absence of prediction of outcome by a high DPG will occur in heart failure populations with a very low proportion of pulmonary vascular disease, as typically seen in patients on waiting lists for cardiac transplantation [20]. Patients with a $\mathrm{Cpc}-\mathrm{PH}$ phenotype are unlikely to be referred for cardiac transplantation because of a well-known associated high operative risk $[10,11]$. Furthermore, the right ventricle's functional adaptation to afterload may matter more to prognosis than only $\mathrm{PH}$ and related vascular gradients $[21,22]$, and measurements for phenotyping do not solely qualify by prognostic capability $[22,23]$. In the meantime, several studies have nevertheless confirmed the impact on outcome of an increased DPG in PH-LHD [24-27].

The diagnosis of pulmonary vascular disease in patients with LHD is more than just a new game of acronyms for dedicated experts [28]. While the onset of $\mathrm{PH}$ in heart failure heralds a decreased life expectancy [2-4], increased risk for pulmonary vascular disease worsens prognosis even more. The prevalence of $\mathrm{Cpc}-\mathrm{PH}$ in $\mathrm{PH}-\mathrm{LHD}$ is, fortunately, relatively low. In the experience of Gerges and co-workers, it would amount to $16 \%$ if defined by a combination of increased DPG and TPG [5] and to $14 \%$ if defined by a combination of increased DPG and PVR $[1,6]$. So-defined Cpc-PH may have a life expectancy comparable to that of untreated pulmonary arterial hypertension $[5,6]$.

Whether Cpc-PH is at least partially amenable to treatments aiming at a decrease in left atrial pressure is not exactly known. However, the experience of corrective interventions for mitral stenosis and associated severe PH suggests that PVR may still decrease several months after the return of PAWP within the limits of normal [29]. Trials of treatments targeting the pulmonary circulation in heart failure have been negative until now [2-4]. Some yet unconfirmed exceptions have been reported in small monocentric series of patients with PH-LHD who also presented with high DPG and right ventricular filling pressures, thus 
suggestive of a Cpc-PH phenotype [30]. This calls for re-designed and dedicated multicentric randomised controlled trials. Further study of the potential molecular and physiological risks for development of $\mathrm{Cpc}-\mathrm{PH}$ is also needed to prevent or treat this particular phenotype of PH-LHD.

Gerges and co-workers are to be commended for several recent major contributions to the understanding of PH-LHD. Their research letter in the present issue of the ERJ should be a last addition for a definitive expert consensus phenotyping of pulmonary vascular complications of left heart conditions, and accordingly help to pave the way for much needed therapeutic progress in these patients.

\section{References}

1 Gerges M, Gerges C, Lang IM. How to define pulmonary hypertension due to left heart disease. Eur Respir J 2016; 48: 553-555.

2 Vachiéry JL, Adir Y, Barberà JA, et al. Pulmonary hypertension due to left heart diseases. J Am Coll Cardiol 2013; 62: Suppl. 25, D100-D108.

3 Rosenkranz S, Gibbs JS, Wachter R, et al. Left ventricular heart failure and pulmonary hypertension. Eur Heart J 2016; 37: 942-954.

4 Galiè N, Humbert M, Vachiery JL, et al. 2015 ESC/ERS Guidelines for the diagnosis and treatment of pulmonary hypertension. Eur Respir J 2015; 46: 903-975.

5 Gerges C, Gerges M, Lang MB, et al. Diastolic pulmonary vascular pressure gradient: a predictor of prognosis in "out-of-proportion" pulmonary hypertension. Chest 2013; 143: 758-766.

6 Gerges M, Gerges C, Pistritto AM, et al. Pulmonary hypertension in heart failure. Epidemiology, right ventricular function, and survival. Am J Respir Crit Care Med 2015; 192: 1234-1246.

7 Cournand A, Bloomfield RA, Lauson HD. Double lumen catheter for intravenous and intracardiac blood sampling and pressure recording. Proc Soc Exp Biol Med 1945; 60: 73-75.

8 Parker F Jr, Weiss S. The nature and significance of the structural changes in the lungs in mitral stenosis. Am J Pathol 1936; 12: 573-598.

9 Wood P. Pulmonary hypertension with special reference to the vasoconstrictive factor. Br Heart J 1958; 20: 557-570.

10 Murali S, Kormos RL, Uretsky BF, et al. Preoperative pulmonary hemodynamics and early mortality after orthotopic cardiac transplantation: the Pittsburgh experience. Am Heart J 1993; 126: 896-904.

11 Fang JC, DeMarco T, Givertz MM, et al. World Health Organization Pulmonary Hypertension Group 2: Pulmonary hypertension due to left heart disease in the adult - a summary statement from the Pulmonary Hypertension Council of the International Society for Heart and Lung Transplantation. J Heart Lung Transplant 2012; 31: 913-933.

12 Dalen JE, Dexter L, Ockene IS, et al. Precapillary pulmonary hypertension; its relationship to pulmonary venous hypertension. Trans Am Clin Climatol Assoc 1975; 86: 207-218.

13 Guazzi M, Borlaug BA. Pulmonary hypertension due to left heart disease. Circulation 2012; 126: 975-990.

14 Naeije R, Vachiery JL, Yerly P, et al. The transpulmonary pressure gradient for the diagnosis of pulmonary vascular disease. Eur Respir J 2013; 41: 217-223.

15 Stevens PM. Assessment of acute respiratory failure: cardiac versus pulmonary causes. Chest 1975; 67: 1-2.

16 Harvey RM, Enson Y, Ferrer MI. A reconsideration of the origins of pulmonary hypertension. Chest 1971; 59: 82-94.

17 Halpern SD, Taichman DB. Misclassification of pulmonary hypertension due to reliance on pulmonary capillary wedge pressure rather than left ventricular end-diastolic pressure. Chest 2009; 136: 37-43.

18 Tampakakis E, Leary PJ, Selby VN, et al. The diastolic pulmonary gradient does not predict survival in patients with pulmonary hypertension due to left heart disease. JACC Heart Fail 2015; 3: 9-16.

19 Gerges C, Gerges M, Lang IM. Characterization of pulmonary hypertension in heart failure using the diastolic pressure gradient: the conundrum of high and low diastolic pulmonary gradient. JACC Heart Fail 2015; 3: 424-425.

20 Tedford RJ, Beaty CA, Mathai SC, et al. Prognostic value of the pre-transplant diastolic pulmonary artery pressure-to-pulmonary capillary wedge pressure gradient in cardiac transplant recipients with pulmonary hypertension. J Heart Lung Transplant 2014; 33: 289-297.

21 Chatterjee NA, Lewis GD. Characterization of pulmonary hypertension in heart failure using the diastolic pressure gradient: limitations of a solitary measurement. JACC Heart Fail 2015; 3: 17-21.

22 Brittain EL, Assad TR, Hemnes AR, et al. The diastolic pressure gradient does not - and should not - predict outcomes. JACC Heart Fail 2015; 3: 845.

23 Naeije R. Measurement to predict survival: the case of diastolic pulmonary gradient. JACC Heart Fail 2015; 3: 425.

24 Dragu R, Rispler S, Habib M, et al. Pulmonary arterial capacitance in patients with heart failure and reactive pulmonary hypertension. Eur J Heart Fail 2015; 17: 74-80.

25 Ibe T, Wada H, Sakakura K, et al. Pulmonary hypertension due to left heart disease: the prognostic implications of diastolic pulmonary vascular pressure gradient. J Cardiol 2016; 67: 555-559.

26 O'Sullivan CJ, Wenaweser P, Ceylan O, et al. Effect of pulmonary hypertension hemodynamic presentation on clinical outcomes in patients with severe symptomatic aortic valve stenosis undergoing transcatheter aortic valve implantation: insights from the new proposed pulmonary hypertension classification. Circ Cardiovasc Interv 2015; 8: e002358.

27 Nichols EL, Rezaee ME, Brown JR. One-year survival in heart failure patients with preserved ejection fraction and isolated post-capillary or combined post- and pre-capillary pulmonary hypertension. Circulation 2015; 132: Suppl. 3, A14302.

28 Vanderpool RR, Naeije R. Progress in pulmonary hypertension with left heart failure. Beyond new definitions and acronyms. Am J Respir Crit Care Med 2015; 192: 1152-1154.

29 Zener JC, Hancock EW, Shumway NE, et al. Regression of extreme pulmonary hypertension after mitral valve surgery. Am J Cardiol 1972; 30: 820-826.

30 Guazzi M, Vicenzi M, Arena R, et al. Pulmonary hypertension in heart failure with preserved ejection fraction: a target of phosphodiesterase-5 inhibition in a 1-year study. Circulation 2011; 124: 164-174. 